\title{
Sliding Mode Observer-based MRAS for Sliding Mode DTC of Induction Motor: Electric Vehicle
}

\author{
Abdelkader Ghezouani ${ }^{1}$, Brahim Gasbaoui ${ }^{1}$, and Jamel Ghouili ${ }^{2}$ \\ ${ }^{1}$ Laboratory of Smart Grids \& Renewable Energies (S.G.R.E), Faculty of Technology, \\ Department of Electrical Engineering, Bechar University, B.P 417, 08000, Algeria; \\ ${ }^{2}$ Department of Electrical Engineering, Moncton University Pavilion Leopold-Taillon, 18, \\ Avenue Antonine - Maillet, Moncton, NB, E1A 3E9, Canada.
}

\begin{abstract}
The current paper presents a new, Direct Torque and Flux Control strategy based on sliding mode control (SMC) and space-Vector Modulation (SVM) is proposed for induction motor Sensorless drives in order to solve existing problems in conventional control by Direct Torque Control (C-DTC); such as, high flux, torque and current ripple, and variable switching frequency. The presence of hysteresis comparators is the major reason for high torque and flux ripples in C-DTC. In SM-DTC, the hysteresis comparators and switching Table are replaced by sliding mode controller. The stability and robustness of the controller are proven analytically using the Lyapunov theory. To avoid the use of a mechanical sensor, the rotor speed estimation is made by a sliding mode observer (SMO) based model reference adaptive system (MRAS). The reference model is a Sensorless sliding mode observer and the adaptive model is a typical current model. Finally, the proposed schemes are simulated under Matlab / Simulink environment, and the simulation results show the effectiveness of the proposed Sensorless control.
\end{abstract}

Keywords: induction motor, direct torque control (DTC), space vector modulation (SVM), sliding mode control (SMC), sliding mode observer (SMO), model reference adaptive system (MRAS).

\section{Introduction}

In traction systems, the overall performance of an electric vehicle depends largely on the type of engine used. Among several types of electric motors, induction motors offer the best choice because of their good performance: reliable operation, robustness, low cost of purchase and virtually zero maintenance, mass power [1-2-3]. However, these advantages have long been inhibited by the complexity of the control because of the following reasons:

- The model of the machine is nonlinear.

- Electric rotor variables are not measurable.

- Physical parameters are most often imprecise and unknown (presence of parametric uncertainties).

Many modern control methods have been applied to the control of the induction machine. The direct DTC torque control technique has been widely used in industry [4]. Compared to vector control, this technique is characterized by simplicities, high performance, and robustness. In the DTC, a switching table is used to determine the control voltage vector as a function of torque and flux error. Despite its simplicity, the direct control of the torque, with several disadvantages, exhibits corrugations at the level of the torque: a deformation of the flux at low speed, producing noise, vibrations, and losses. To solve these problems, several modern control methods have been developed to improve the performance of conventional DTC. These have; namely, evolved:

- The comparators and switching tables improved while the original topology is unchanged [5-6].

- Solutions that implement the concept DTC my means space vector modulation (SVM) [7-8].

- Couple and flux explicitly use variable structure (VSC) [9-10].

Received: February $2^{\text {nd }}, 2018$. Accepted: July $24^{\text {th }}, 2019$

DOI: $10.15676 /$ ijeei.2019.11.3.9 
This article proposes a family of variable structures combined with the SVM technique for the control of the $15 \mathrm{KW}$ power induction machine without a data sensor used to drive the wheels of an electric vehicle to four Wheel drive (EV4WD). The direct torque and flow control is implemented in VSC; the SVM is to reduce the torque and are ripple and ensures a constant switching frequency. Most of the work reported in the literature deal separately with the problem of the suppression of the sensor of events and that of lack of robustness of the control with respect to the parameter variable. Thus, the objective of this paper is to propose a direct control of the couple based on the SMC and SVM technique equipped with a Sensorless control based on the Sliding mode observer based MRAS technique. This in order to improve the performance of the speed estimator in terms of precision and convergence.

\section{Model of Induction Motor}

The induction motor model, with the stator currents and the stator flux as state variables, in the stationary $(\alpha-\beta)$ reference frame can be expressed by:

$$
\left[\begin{array}{c}
\dot{x} \\
\mathrm{x}_{1} \\
\dot{x_{2}} \\
\mathrm{x}_{3} \\
\mathrm{x}_{3} \\
\mathrm{x}_{4} \\
\dot{x_{5}}
\end{array}\right]=\left[\begin{array}{c}
\mathrm{a}_{1} \mathrm{x}_{1}+\mathrm{a}_{2} \mathrm{x}_{3}+\mathrm{a}_{3} \mathrm{x}_{4} \mathrm{x}_{5} \\
\mathrm{a}_{1} \mathrm{x}_{2}+\mathrm{a}_{2} \mathrm{x}_{4}+\mathrm{a}_{3} \mathrm{x}_{3} \mathrm{x}_{5} \\
\mathrm{a}_{4} \mathrm{x}_{1}+\mathrm{a}_{5} \mathrm{x}_{3}+\mathrm{x}_{4} \mathrm{x}_{5} \\
\mathrm{a}_{4} \mathrm{x}_{2}+\mathrm{a}_{5} \mathrm{x}_{4}+\mathrm{x}_{3} \mathrm{x}_{5} \\
\mathrm{a}_{7}\left(\mathrm{x}_{2} \mathrm{x}_{3}+\mathrm{x}_{1} \mathrm{x}_{4}\right)+\mathrm{a}_{8} \mathrm{x}_{5}+\mathrm{a}_{9} \mathrm{~T}_{\mathrm{L}}
\end{array}\right]+\left[\begin{array}{cc}
\alpha & 0 \\
0 & \alpha \\
0 & 0 \\
0 & 0 \\
0 & 0
\end{array}\right] \mathrm{U}
$$

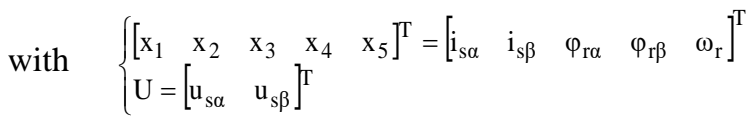

For simplicity, we define the following variables:

$$
\left\{\begin{array}{l}
\mathrm{a}_{1}=-\left(\frac{\mathrm{R}_{\mathrm{s}}}{\sigma \mathrm{L}_{\mathrm{s}}}+\frac{\mathrm{R}_{\mathrm{r}} \mathrm{M}^{2}}{\sigma \mathrm{L}_{\mathrm{s}} \mathrm{L}_{\mathrm{r}}}\right), \mathrm{a}_{2}=\frac{\mathrm{R}_{\mathrm{r}} \mathrm{M}}{\sigma \mathrm{L}_{\mathrm{s}} \mathrm{L}_{\mathrm{r}}^{2}}, \mathrm{a}_{3}=\frac{\mathrm{M}}{\sigma \mathrm{L}_{\mathrm{s}} \mathrm{L}_{\mathrm{r}}} \\
\mathrm{a}_{4}=\frac{\mathrm{M}}{\mathrm{T}_{\mathrm{r}}}, \mathrm{a}_{5}=\frac{1}{\mathrm{~T}_{\mathrm{r}}}, \mathrm{a}_{6}=\mathrm{p}, \mathrm{a}_{7}=\frac{3}{2} \frac{\mathrm{p}^{2} \mathrm{M}}{\mathrm{JL}_{\mathrm{r}}}, \mathrm{a}_{8}=-\frac{\mathrm{Pf}_{\mathrm{c}}}{\mathrm{J}} \\
\mathrm{a}_{9}=\frac{\mathrm{P}}{\mathrm{J}}, \mathrm{a}_{10}=\frac{3}{2} \mathrm{p}^{2} \frac{\mathrm{M}}{\mathrm{L}_{\mathrm{r}}}, \mathrm{T}_{\mathrm{r}}=\frac{\mathrm{L}_{\mathrm{r}}}{\mathrm{R}_{\mathrm{r}}}, \sigma=1-\frac{\mathrm{M}^{2}}{\mathrm{~L}_{\mathrm{s}} \mathrm{L}_{\mathrm{r}}}, \alpha=\frac{1}{\sigma \mathrm{L}_{\mathrm{s}}}
\end{array}\right.
$$

The estimated Torque and the square module of rotor flux linkage $\left|\varphi_{r}\right|^{2}$ is given by

$$
\left[\begin{array}{c}
\mathrm{T}_{\mathrm{e}} \\
\left|\varphi_{\mathrm{r}}\right|^{2}
\end{array}\right]=\left[\begin{array}{c}
\mathrm{a}_{10}\left(\mathrm{x}_{2} \mathrm{x}_{3}-\mathrm{x}_{1} \mathrm{x}_{4}\right) \\
\mathrm{x}_{3}^{2}+\mathrm{x}_{4}^{2}
\end{array}\right]
$$

Where $u_{s \alpha}, u_{s \beta}, \phi_{r \alpha}, \phi_{r \beta}, i_{s \alpha}, i_{s \beta}$ are respectively the stator voltage, rotor flux and stator current vector components in $(\alpha-\beta)$ stator coordinate system; $\omega_{r}$ is the rotor electrical angular; $\mathrm{L}_{\mathrm{s}}, L_{r}, M$ are stator, rotor and magnetizing inductances respectively; $\mathrm{R}_{\mathrm{s}}, R_{r}$ are respectively stator and rotor resistances; $\mathrm{T}_{\mathrm{e}}$ and $T_{L}$ is electromagnetic torque and load torque; $\mathrm{J}, \mathrm{f}_{\mathrm{c}}$ are the rotor inertia and fractional coefficient ; $\mathrm{p}$ is the number of pairs poles .

\section{Sliding Mode Direct Torque Control of IM}

The basic configuration of proposed control structure is presented in Figure 1. In a scheme the torque and rotor flux of an induction motor are controlled by a sliding mode controller. The reference rotor speed $x_{5}^{r e f}$ and the square of rotor flux $\phi_{\text {ref }}$ are the input variables. The output of the sliding mode speed controller is the reference torque $T_{e}^{r e f}$. The differences between torque (rotor flux respectively) reference values and observer values are delivered to SM-DTC block; the results of the controller (SMDTC) are the reference voltage $\left(u_{s \alpha}^{*}, u_{s \beta}^{*}\right)$. This is realized in the inverter using space vector modulation (SVM). Where the rotor flux is estimated with sliding 
mode observer. The objective of SM-DTC design is to make the modulus of the rotor flux vector $\phi_{r}$ and torque $T_{e}$ track to their reference value $T_{e}^{r e f}$ and $\phi_{r}^{r e f}$ respectively.

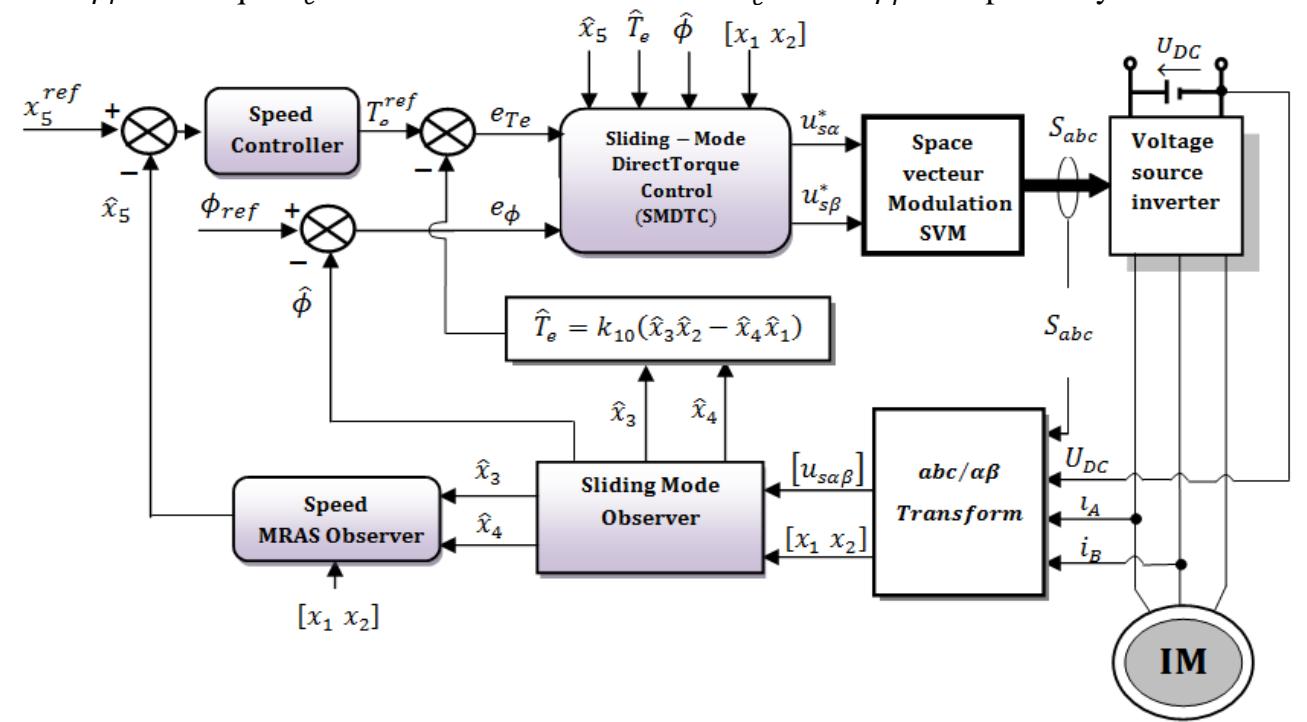

Figure 1. Proposed Sliding Mode Direct Torque Control (SM-DTC) for Sensorless IM drives scheme.

\section{A. Design of the Sliding Mode Torque and Rotor Flux Controller}

Define the errors as:

$$
\left\{\begin{array}{l}
\mathrm{e}_{\mathrm{Te}}=\hat{\mathrm{T}}_{\mathrm{e}}-\mathrm{T}_{\mathrm{e}}^{\mathrm{ref}} \\
\mathrm{e}_{\varphi}=\hat{\varphi}-\varphi_{\mathrm{ref}}
\end{array}\right.
$$

Where $T_{e}^{\text {ref }}$ and $\phi_{\text {ref }}$ are respectively the references of torque and rotor flux norm.

$$
\hat{\varphi}=\left|\hat{\varphi}_{\mathrm{r}}\right|^{2}=\hat{\mathrm{x}}_{3}^{2}+\hat{\mathrm{x}}_{4}^{2}
$$

Where, $\hat{T}_{e}$ and $\hat{\varphi}_{r}$ are the estimated Torque and rotor Flux; $\hat{x}_{3}, \hat{x}_{4}$ are the estimated rotor flux in $(\alpha-\beta)$ coordinate

\section{- Selection of the Sliding Surfaces}

The sliding mode Torque and Flux surface $S=\left[\begin{array}{ll}S_{1} & S_{2}\end{array}\right]^{T}$ is selected as:

$$
\left\{\begin{array}{l}
\mathrm{S}_{1}=\mathrm{e}_{\mathrm{Te}}+\mathrm{c}_{1} \int_{0}^{\mathrm{t}} \mathrm{e}_{\mathrm{Te}}(\tau) \mathrm{d} \tau \\
\mathrm{S}_{2}=\mathrm{e}_{\varphi}+\mathrm{c}_{2} \mathrm{e}_{\varphi}
\end{array}\right.
$$

Where $C_{1}$ and $C_{2}$ are positive constants.

The time derivatives of $(S)$ we obtain the dynamical equations of the switching surface variables as

$$
\begin{aligned}
& \left\{\begin{array}{l}
\dot{\mathrm{S}}_{1}=\mathrm{e}_{\mathrm{Te}}+\mathrm{c}_{1} \mathrm{e}_{\mathrm{Te}}=\left(\dot{\mathrm{T}}_{\mathrm{e}}-\mathrm{T}_{\mathrm{e}}^{\mathrm{ref}}\right)+\mathrm{c}_{1}\left(\hat{\mathrm{T}}_{\mathrm{e}}-\mathrm{T}_{\mathrm{e}}^{\mathrm{ref}}\right) \\
\dot{\mathrm{S}}_{2}=\ddot{\mathrm{e}_{\varphi}}+\mathrm{c}_{2} \dot{\mathrm{e}}_{\varphi}=\left(\ddot{\hat{\varphi}}-\ddot{\varphi}{ }_{\mathrm{ref}}\right)+\mathrm{c}_{2}\left(\dot{\hat{\varphi}}-\dot{\varphi}_{\mathrm{ref}}\right)
\end{array}\right. \\
& \left\{\begin{array}{l}
\dot{\mathrm{S}}_{1}=\mathrm{a}_{10}\left(\dot{\mathrm{x}}_{2} \hat{\mathrm{x}}_{3}+\mathrm{x}_{2} \dot{\mathrm{x}}_{3}-\dot{\mathrm{x}}_{1} \hat{\mathrm{x}}_{4}-\mathrm{x}_{1} \dot{\mathrm{x}}_{4}-\mathrm{T}_{\mathrm{e}}^{\mathrm{ref}}\right)+\mathrm{c}_{1}\left(\hat{\mathrm{T}}_{\mathrm{e}}-\mathrm{T}_{\mathrm{e}}^{\mathrm{ref}}\right) \\
\dot{\mathrm{S}}_{2}=2\left(\mathrm{a}_{4}\left(\dot{\mathrm{x}}_{1} \hat{\mathrm{x}}_{3}+\mathrm{x}_{1} \dot{\mathrm{x}}_{3}+\dot{\mathrm{x}}_{2} \hat{\mathrm{x}}_{4}+\mathrm{x}_{2} \dot{\mathrm{x}}_{4}\right)+\mathrm{a}_{5} \dot{\hat{\varphi}}\right)-\dot{\varphi}_{\mathrm{ref}}+\mathrm{c}_{2} \mathrm{e}_{\varphi}
\end{array}\right.
\end{aligned}
$$


By substituting $\dot{x}_{1}, \dot{x}_{2}, \dot{x}_{3}, \dot{x}_{4}$ from (1) into (9), we obtain

$$
\left\{\begin{array}{l}
\dot{\mathrm{S}}_{1}=\mathrm{a}_{10}\left[\left(\mathrm{c}_{1}+\mathrm{a}_{1}-\mathrm{a}_{5}\right) \mathrm{l}_{2}-\hat{\mathrm{x}}_{5}\left(\mathrm{a}_{3} \varphi+\mathrm{l}_{1}\right)\right]-\mathrm{a}_{10} \mathrm{~T}_{\mathrm{e}}^{\mathrm{ref}}-\mathrm{c}_{1} \mathrm{~T}_{\mathrm{e}}^{\mathrm{ref}}+\mathrm{a}_{10} \alpha\left(\hat{\mathrm{x}}_{3} \mathrm{u}_{\mathrm{s} \beta}-\hat{\mathrm{x}}_{4} \mathrm{u}_{\mathrm{s} \alpha}\right) \\
\dot{\mathrm{S}}_{2}=\left(\mathrm{c}_{2}+2 \mathrm{a}_{5}\right) \dot{\hat{\varphi}}+2 \mathrm{a}_{4}\left[\left(\mathrm{a}_{1}+\mathrm{a}_{5}\right) \mathrm{l}_{1}+\mathrm{a}_{2} \hat{\varphi}+\mathrm{a}_{4} \mathrm{l}_{3}+\hat{\mathrm{x}}_{5} \mathrm{l}_{2}\right]-\mathrm{c}_{2} \dot{\varphi_{\text {ref }}}-\dot{\varphi}_{\mathrm{ref}}+2 \mathrm{a}_{4} \alpha\left(\hat{\mathrm{x}}_{3} \mathrm{u}_{\mathrm{s} \alpha}+\hat{\mathrm{x}}_{4} \mathrm{u}_{\mathrm{s} \beta}\right)
\end{array}\right.
$$

Where

$$
\left\{\begin{array}{l}
\mathrm{l}_{1}=\mathrm{x}_{1} \hat{\mathrm{x}}_{3}+\mathrm{x}_{2} \hat{\mathrm{x}}_{4} \\
\mathrm{l}_{2}=\mathrm{x}_{2} \hat{\mathrm{x}}_{3}-\mathrm{x}_{1} \hat{\mathrm{x}}_{4} \\
\mathrm{l}_{3}=\mathrm{x}_{1}^{2}+\mathrm{x}_{2}^{2}
\end{array}\right.
$$

\section{- Selection of the Control Law}

The derivatives of sliding surfaces (7) are given in matrix form as follows

$$
\dot{\mathrm{S}}=\mathrm{G}+\mathrm{DU}
$$

Where, $U=\left[\begin{array}{ll}u_{s \alpha} & u_{s \beta}\end{array}\right]^{T}$ is the stator voltage vector of the control law, $G$ and $D$ are matrices calculated as follows

$$
\begin{aligned}
\mathrm{D} & =\left[\begin{array}{ll}
-\alpha \hat{\mathrm{x}}_{4} & \alpha \hat{\mathrm{x}}_{3} \\
2 \mathrm{a}_{4} \alpha \hat{\mathrm{x}}_{3} & 2 \mathrm{a}_{4} \alpha \hat{\mathrm{x}}_{4}
\end{array}\right] \\
\mathrm{G} & =\left[\begin{array}{l}
\mathrm{g}_{1}=\left[\left(\mathrm{c}_{1}+\mathrm{a}_{1}-\mathrm{a}_{5}\right) \mathrm{l}_{2}-\hat{\mathrm{x}}_{5}\left(\mathrm{a}_{3} \hat{\varphi}+\mathrm{l}_{1}\right)\right]-\mathrm{a}_{10} \mathrm{~T}_{\mathrm{e}}^{\text {ref }}-\mathrm{c}_{1} \mathrm{~T}_{\mathrm{e}}^{\text {ref }} \\
\mathrm{g}_{2}=\left(\mathrm{c}_{2}+2 \mathrm{a}_{5}\right) \dot{\varphi}+2 \mathrm{a}_{4}\left[\left(\mathrm{a}_{1}+\mathrm{a}_{5}\right) \mathrm{l}_{1}+\mathrm{a}_{2} \hat{\varphi}+\mathrm{a}_{4} \mathrm{l}_{3}+\hat{\mathrm{x}}_{5} \mathrm{l}_{2}\right]-\mathrm{c}_{2} \dot{\varphi}_{\mathrm{ref}}-\hat{\varphi}_{\text {ref }}
\end{array}\right]
\end{aligned}
$$

The form of the Reaching law used is chosen in order to avoid flux and torque ripples as follows

$$
\left\{\begin{array}{l}
\frac{\mathrm{d}_{1}}{\mathrm{dt}}=-\mu_{1} \operatorname{sgn}\left(\mathrm{S}_{1}\right)-\varepsilon_{1} \mathrm{~S}_{1} \\
\frac{\mathrm{d} \mathrm{S}_{2}}{\mathrm{dt}}=-\mu_{2} \operatorname{sgn}\left(\mathrm{S}_{2}\right)-\varepsilon_{2} \mathrm{~S}_{2}
\end{array}\right.
$$

Where $\mu_{1}, \mu_{2}, \varepsilon_{1}$ and $\varepsilon_{2}$ are control gains, $\operatorname{sign}\left(S_{1}\right)$ and $\operatorname{sign}\left(S_{2}\right)$ is the sign function as follows

$$
\operatorname{sign}(S)=\left\{\begin{array}{l}
1 \quad \text { if } \quad S \succ 0 \\
-1 \text { if } \quad S \prec 0
\end{array}\right.
$$

If the system stays stationary on the surface, then

$$
\left\{\begin{array}{l}
\mathrm{S}_{1}=0 \Rightarrow \dot{\mathrm{S}_{1}}=0 \\
\mathrm{~S}_{2}=0 \Rightarrow \dot{\mathrm{S}_{2}}=0
\end{array}\right.
$$

By substituting (15) into (12), the stator voltage vector in the stationary $(\alpha, \beta)$ reference frame is calculated as follows [11].

$$
\mathrm{U}=\left[\begin{array}{c}
\mathrm{u}_{\mathrm{s} \alpha}^{*} \\
\mathrm{u}_{\mathrm{s} \beta}{ }^{*}
\end{array}\right]=-\mathrm{D}^{-1}\left[\begin{array}{c}
\mathrm{g}_{1}+\mu_{1} \operatorname{sgn}\left(\mathrm{S}_{1}\right)+\varepsilon_{1} \mathrm{~S}_{1} \\
\mathrm{~g}_{2}+\mu_{2} \operatorname{sgn}\left(\mathrm{S}_{2}\right)+\varepsilon_{2} \mathrm{~S}_{2}
\end{array}\right]
$$

Where $\mathrm{u}_{\mathrm{s} \alpha}{ }^{*}$ and $\mathrm{u}_{\mathrm{s} \beta}{ }^{*}$ is the controlling law of flux rotor and electromagnetic torque respectively. Considering the uncertainties parameters influence (e.g. $R s, R r, L s, L r, M$ ), equation (12) can be rewritten as

$$
\dot{\mathrm{S}}=(\mathrm{G}+\Delta \mathrm{G})+(\mathrm{D}+\Delta \mathrm{D}) \mathrm{U}=\mathrm{G}+\mathrm{DU}+\left[\begin{array}{l}
\delta_{1} \\
\delta_{2}
\end{array}\right]
$$


Where $\delta_{1}, \delta_{2}$ are the lumped uncertainties defined as follows

$$
\left[\begin{array}{c}
\delta_{1} \\
\delta_{2}
\end{array}\right]=\left[\begin{array}{c}
\Delta \mathrm{g}_{1}+\Delta \mathrm{d}_{11} \mathrm{U}_{1}+\Delta \mathrm{d}_{12} \mathrm{U}_{2} \\
\Delta \mathrm{g}_{2}+\Delta \mathrm{d}_{21} \mathrm{U}_{1}+\Delta \mathrm{d}_{22} \mathrm{U}_{2}
\end{array}\right]
$$

By defining Lyapunov, function as,

$$
\mathrm{V}_{1}(\mathrm{t})=\frac{1}{2} \mathrm{~S}^{\mathrm{T}}(\mathrm{t}) \mathrm{S}(\mathrm{t})
$$

The stability condition can be obtained from the Lyapunov stability theorem as

$$
\begin{aligned}
& \dot{\mathrm{V}}_{1}(\mathrm{t})=\mathrm{S}^{\mathrm{T}}(\mathrm{t}) \dot{\mathrm{S}}(\mathrm{t})=\left[\begin{array}{ll}
\mathrm{S}_{1} & \mathrm{~S}_{2}
\end{array}\right] \cdot\left[\begin{array}{l}
-\mu_{1} \operatorname{sgn}\left(\mathrm{S}_{1}\right)-\varepsilon_{1} \mathrm{~S}_{1}+\delta_{1} \\
-\mu_{2} \operatorname{sgn}\left(\mathrm{S}_{2}\right)-\varepsilon_{2} \mathrm{~S}_{2}+\delta_{2}
\end{array}\right] \\
& =-\varepsilon_{1} \mathrm{~S}_{1}{ }^{2}-\varepsilon_{2} \mathrm{~S}_{2}{ }^{2}-\mu_{1}\left|\mathrm{~S}_{1}\right|-\mu_{2}\left|\mathrm{~S}_{2}\right|+\delta_{1} \mathrm{~S}_{1}+\delta_{2} \mathrm{~S}_{2}
\end{aligned}
$$

Then by choosing $u_{1}=\max \left(\delta_{1}\right)$ and $u_{2}=\max \left(\delta_{2}\right)$

$$
\dot{\mathrm{V}}_{1}(\mathrm{t}) \leq-\varepsilon_{1} \mathrm{~S}_{1}^{2}-\varepsilon_{2} \mathrm{~S}_{2}^{2}
$$

By Lyapunov theory the stability of the system (23) is guaranteed

\section{B. Design of the Sliding Mode Speed Controller}

In the mechanical (1) equation of induction motor the angular rotor speed is written as:

$$
\dot{\hat{\mathrm{x}}}_{5}=\mathrm{a}_{9}\left(\mathrm{~T}_{\mathrm{e}}+\mathrm{T}_{\mathrm{L}}\right)+\mathrm{a}_{8} \hat{\mathrm{x}}_{5}
$$

Setting $f=a_{9} T_{L}$. Then (24) is transferred as

$$
\dot{\hat{\mathrm{x}}}_{5}=\mathrm{a}_{9} \mathrm{~T}_{\mathrm{e}}+\mathrm{a}_{8} \hat{\mathrm{x}}_{5}+\mathrm{f}
$$

Considering uncertainties influence, (25) can be rewritten as

$$
\dot{\hat{\mathrm{x}}}_{5}=\left(\mathrm{a}_{9}+\Delta \mathrm{a}_{9}\right) \mathrm{T}_{\mathrm{e}}+\left(\mathrm{a}_{8}+\Delta \mathrm{a}_{8}\right) \hat{\mathrm{x}}_{5}+(\mathrm{f}+\Delta \mathrm{f})=\mathrm{a}_{9} \mathrm{~T}_{\mathrm{e}}{ }^{\text {ref }}+\mathrm{a}_{8} \hat{\mathrm{x}}_{5}+\mathrm{f}+\mathrm{L}(\mathrm{t})
$$

Where $\Delta a_{8}, \Delta a_{9}$ and $\Delta f$ represents the uncertainties of the terms $\mathrm{a}_{8}, \mathrm{a}_{9}$ and f respectively. $L(t)$ is called Lumped uncertainty, and is obtained as [12].

$$
\mathrm{L}(\mathrm{t})=\Delta \mathrm{a}_{9} \mathrm{~T}_{\mathrm{e}}+\Delta \mathrm{a}_{8} \hat{\mathrm{x}}_{5}+\Delta \mathrm{f}
$$

The tracking speed error is written as:

$$
\mathrm{e}\left(\mathrm{x}_{5}\right)=\hat{\mathrm{x}}_{5}-\mathrm{x}_{5}^{\text {ref }}
$$

Then, the derivative of (28) can be represented as:

$$
\dot{\mathrm{e}}\left(\mathrm{x}_{5}\right)=\dot{\hat{\mathrm{x}}}_{5}-\dot{\hat{\mathrm{x}}}_{5}{ }^{\text {ref }}=\mathrm{a}_{8} \mathrm{e}(\mathrm{t})+\mathrm{u}(\mathrm{t})+\mathrm{L}(\mathrm{t})
$$

Where $\quad u(t)=a_{9} T_{e}+a_{8} x_{5}^{\text {ref }}+f(t)-x_{5}^{\text {ref }}$

The time-varying surface of the sliding mode can be defined with integral component as [13]

$$
\mathrm{S}_{3}(\mathrm{t})=\mathrm{e}(\mathrm{t})-\left(\mathrm{a}_{8}+\lambda\right) \int_{0}^{\mathrm{t}} \mathrm{e}(\tau) \mathrm{d} \tau
$$

The derivative of (28) can be written as

$$
\dot{S_{3}}(\mathrm{t})=\dot{\mathrm{e}}(\mathrm{t})-\left(\mathrm{a}_{8}+\lambda\right) \mathrm{e}(\mathrm{t})
$$

\section{- Selection of the Control Law}

When the sliding mode occurs on the sliding surface, then $S_{3}(t)=\dot{S}_{3}(t)=0$ and therefore the dynamical behavior of the tracking problem in (32) is equivalently governed by the following

$$
\dot{\mathrm{e}}(\mathrm{t})=\left(\mathrm{a}_{8}+\lambda\right) \mathrm{e}(\mathrm{t})
$$

In order to guarantee good quality during non-sliding process and the reaching condition, the variable structure speed controller is designed as 


$$
\mathrm{u}(\mathrm{t})=\lambda \mathrm{e}(\mathrm{t})-\beta \operatorname{sgn}\left(\mathrm{S}_{3}\right)
$$

Where $\beta$ is a switching gain, $\operatorname{sign}\left(S_{3}\right)$ is the sign function

During the sliding mode and in permanent regime, we have $S_{3}(t)=\dot{S}_{3}(t)=0$ and without consideration of lumped uncertainty $L(t)=0$.

Finally, the reference Torque control $T_{e}^{r e f}$ can be obtained directly substituting (34) in (30).

$$
\mathrm{T}_{\mathrm{e}}^{\mathrm{ref}}=\frac{1}{\mathrm{a}_{9}}\left[\lambda \mathrm{e}(\mathrm{t})-\beta \operatorname{sgn}\left(\mathrm{S}_{3}\right)-\mathrm{a}_{8} \mathrm{x}_{5}^{\text {ref }}+\dot{\hat{\mathrm{x}}}_{5}^{\text {ref }}-\mathrm{f}\right]
$$

\section{- Stability Study}

A sufficient condition for this behaviour is to choose the control law, $T_{e}^{\text {ref }}$ of (35) if the Lyapunov function defined as

$$
\mathrm{V}_{2}(\mathrm{t})=\frac{1}{2} \mathrm{~S}_{3}(\mathrm{t}) \mathrm{S}_{3}(\mathrm{t})
$$

Its time derivative is calculated as

$$
\begin{aligned}
& \dot{V}_{2}(t)=S_{3}(t) S_{3}(t)=S_{3}(t)\left(\dot{e}(t)-\left(a_{8}+\lambda\right) e(t)\right)=S_{3}(t)\left(L(t)-\beta \operatorname{sgn}\left(S_{3}\right)\right) \\
& =-(|L(t)|-\beta)\left|S_{3}(t)\right| \leq 0
\end{aligned}
$$

Then, by choosing $(|L(t)|-\beta)<0$, and $|S(t)| \neq 0$ the system is asymptotically stable

\section{Rotor Flux Sliding Mode Observer}

The proposed sliding mode observer shown in Figure 2 is based on the original system model, where added correctors are gains with switching terms [14]. The sliding surface is the error between the measured and estimated stator current and sign function is used to restrict this error to zero. In general, the sliding mode observer can be expressed as follows [15-16-17]:

$$
\left[\begin{array}{c}
\dot{\hat{x}}_{1} \\
\dot{\mathrm{x}}_{2} \\
\dot{\hat{\mathrm{x}}}_{3} \\
\hat{\mathrm{x}}_{4}
\end{array}\right]=\left[\begin{array}{l}
\mathrm{a}_{1} \hat{\mathrm{x}}_{1}+\mathrm{a}_{2} \hat{\mathrm{x}}_{3}+\mathrm{a}_{3} \hat{\mathrm{x}}_{4} \mathrm{x}_{5}+\Lambda_{1} \mathrm{I}_{\mathrm{s}} \\
\mathrm{a}_{1} \hat{\mathrm{x}}_{2}+\mathrm{a}_{2} \hat{\mathrm{x}}_{4}-\mathrm{a}_{3} \hat{\mathrm{x}}_{3} \mathrm{x}_{5}+\Lambda_{2} \mathrm{I}_{\mathrm{s}} \\
\mathrm{a}_{4} \hat{\mathrm{x}}_{1}-\mathrm{a}_{5} \hat{\mathrm{x}}_{3}-\hat{\mathrm{x}}_{4} \mathrm{x}_{5}+\Lambda_{3} \mathrm{I}_{\mathrm{s}} \\
\mathrm{a}_{4} \hat{\mathrm{x}}_{2}-\mathrm{a}_{5} \hat{\mathrm{x}}_{4}+\hat{\mathrm{x}}_{3} \mathrm{x}_{5}+\Lambda_{4} \mathrm{I}_{\mathrm{s}}
\end{array}\right]+\left[\begin{array}{cc}
\alpha & 0 \\
0 & \alpha \\
0 & 0 \\
0 & 0 \\
0 & 0
\end{array}\right]\left[\begin{array}{l}
\mathrm{u}_{\mathrm{s} \alpha} \\
\mathrm{u}_{\mathrm{s} \beta}
\end{array}\right]
$$

Where, $\hat{x}_{1}, \hat{x}_{2}, \hat{x}_{3}$ and $\hat{x}_{4}$ are the estimates of $x_{1}, x_{2}, x_{3}$ and $x_{4}$ respectively; $\Lambda_{1}, \Lambda_{2}, \Lambda_{3}$ and $\Lambda_{4}$ are the observer's gains in synthesizing advice $\Lambda_{j}=\left[\begin{array}{ll}\Lambda_{j 1} & \Lambda_{j 2}\end{array}\right]$ for $j=1,2,3,4$.

The vector $I_{S}$ is given by:

$$
\mathrm{I}_{\mathrm{S}}=\left[\begin{array}{l}
\operatorname{sign}\left(\mathrm{S}_{1}\right) \\
\operatorname{sign}\left(\mathrm{S}_{2}\right)
\end{array}\right]
$$

Moreover, the sliding surfaces are defined as follows:

$$
\mathrm{S}=\left[\begin{array}{l}
\mathrm{S}_{4} \\
\mathrm{~S}_{5}
\end{array}\right]=\Gamma\left[\begin{array}{c}
\mathrm{x}_{1}-\hat{\mathrm{x}}_{1} \\
\mathrm{x}_{2}-\hat{\mathrm{x}}_{2}
\end{array}\right]
$$

Where

$$
\left\{\begin{array}{l}
\Gamma=\frac{1}{\mathrm{~T}}\left[\begin{array}{cc}
\mathrm{a}_{2} & -\mathrm{a}_{3} \mathrm{x}_{5} \\
\mathrm{a}_{3} \mathrm{x}_{5} & \mathrm{a}_{2}
\end{array}\right] \\
\mathrm{T}=\left(\mathrm{a}_{2}\right)^{2}+\left(\mathrm{a}_{3} \mathrm{x}_{5}\right)^{2}
\end{array}\right.
$$

The choice $\Gamma$ is made to get a simple observer gains synthesis. 


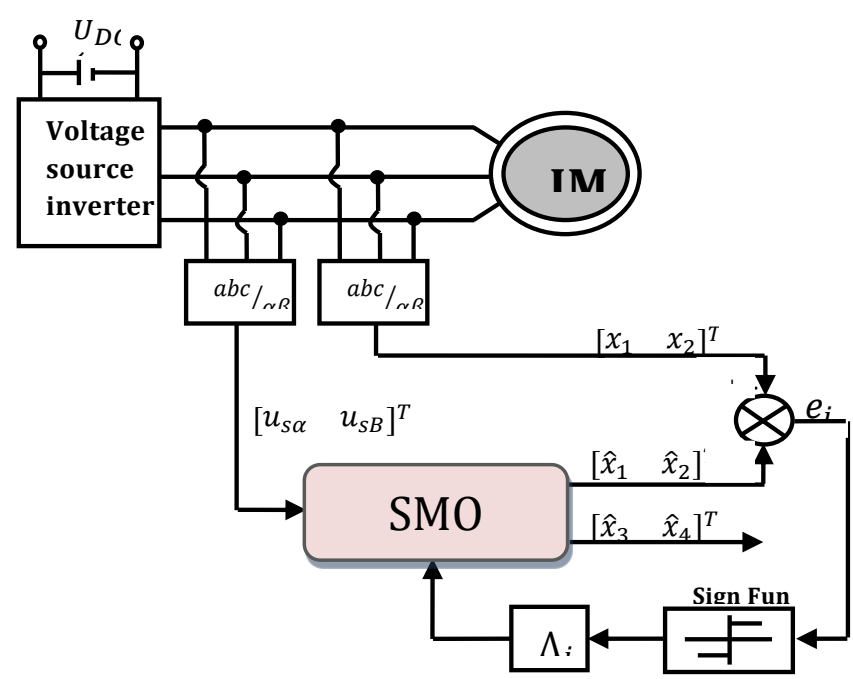

Figure 2. Structure of sliding mode observer (SMO).

Subtracting (1) from (38), the estimation error dynamics can be expressed in matrix from as:

$$
\left\{\begin{array}{l}
\dot{e_{1}}=a_{2} e_{3}+a_{3} x_{5} e_{4}-\Lambda_{1} I_{s} \\
\dot{e_{2}}=a_{2} e_{4}-a_{3} x_{5} e_{3}-\Lambda_{2} I_{s} \\
\dot{e_{3}}=-a_{5} e_{3}-x_{5} e_{4}-\Lambda_{3} I_{s} \\
\dot{e_{4}}=-a_{5} e_{4}+x_{5} e_{3}-\Lambda_{4} I_{s}
\end{array}\right.
$$

Where,

$$
\left[\begin{array}{l}
e_{1} \\
e_{2} \\
e_{3} \\
e_{4}
\end{array}\right]=\left[\begin{array}{l}
x_{1}-\hat{x}_{1} \\
x_{2}-\hat{x}_{2} \\
x_{3}-\hat{x}_{3} \\
x_{4}-\hat{x}_{4}
\end{array}\right]
$$

Are the stator currents and rotor flux estimation errors.

The observer's synthesis therefore consists of determining gain $\Lambda_{1}$ and $\Lambda_{2}$ in order to ensure the attractiveness of the sliding surface $S=0$ and to calculate $\Lambda_{3}$ and $\Lambda_{4}$ such that the reduced order system obtained $S(t)=\dot{S}(t)=0$ when is locally stable.

\section{A. Attractiveness of the sliding surface}

Let us choose the function of Lyapunov candidate

$$
\mathrm{V}_{3}=\frac{1}{2} \mathrm{~S}^{\mathrm{T}} \mathrm{S}
$$

The condition of attractiveness of the surface $S=0$ is given by:

$$
\dot{\mathrm{V}}_{3}=\mathrm{S}^{\mathrm{T}} \dot{\mathrm{S}} \prec 0 \quad \forall \mathrm{s} \neq 0
$$

Where,

$$
\dot{\mathrm{S}}=\dot{\Gamma}\left[\begin{array}{l}
\mathrm{e}_{1} \\
\mathrm{e}_{2}
\end{array}\right]+\Gamma\left[\begin{array}{l}
\dot{\mathrm{e}_{1}} \\
\dot{\mathrm{e}_{2}}
\end{array}\right]=\Gamma\left[\left(\begin{array}{cc}
\mathrm{a}_{2} & \mathrm{a}_{3} \mathrm{x}_{5} \\
-\mathrm{a}_{3} \mathrm{x}_{5} & \mathrm{a}_{2}
\end{array}\right)\left(\begin{array}{l}
\mathrm{e}_{3} \\
\mathrm{e}_{4}
\end{array}\right)-\left(\begin{array}{cc}
\Lambda_{11} & \Lambda_{12} \\
\Lambda_{21} & \Lambda_{22}
\end{array}\right)\left(\begin{array}{cc}
\operatorname{sign} & \left(\mathrm{S}_{4}\right) \\
\operatorname{sign} & \left(\mathrm{S}_{5}\right)
\end{array}\right)+\dot{\Gamma}\left(\begin{array}{l}
\mathrm{e}_{1} \\
\mathrm{e}_{2}
\end{array}\right)\right]
$$


Where,

$$
\begin{aligned}
& \dot{\Gamma}=\left[\begin{array}{cc}
\mathrm{m}_{1} & -\mathrm{m}_{2} \\
\mathrm{~m}_{2} & \mathrm{~m}_{1}
\end{array}\right] \\
& \text { and }\left\{\begin{array}{l}
\mathrm{m}_{1}=-\mathrm{a}_{2} \frac{2\left(\mathrm{a}_{3}\right)^{2} \mathrm{x}_{5} \mathrm{x}_{5}}{\mathrm{~T}^{2}} \\
\mathrm{~m}_{2}=\mathrm{a}_{3} \frac{\left(\mathrm{Tx}_{5}-2\left(\mathrm{a}_{3}\right)^{2} \mathrm{x}_{5} \mathrm{x}_{5}\right)}{\mathrm{T}^{2}}
\end{array}\right.
\end{aligned}
$$

If we put

$$
\left[\begin{array}{ll}
\Lambda_{11} & \Lambda_{12} \\
\Lambda_{21} & \Lambda_{22}
\end{array}\right]=\left[\begin{array}{l}
\Lambda_{1} \\
\Lambda_{2}
\end{array}\right]=\Gamma^{-1} \Delta
$$

Where, $\Delta=\left[\begin{array}{cc}\delta_{1} & 0 \\ 0 & \delta_{2}\end{array}\right]$

$$
\begin{aligned}
& \dot{\mathrm{V}}_{3}=\mathrm{S}^{\mathrm{T}}\left[\left(\begin{array}{l}
\mathrm{e}_{3} \\
\mathrm{e}_{4}
\end{array}\right)-\left(\begin{array}{cc}
\delta_{1} & 0 \\
0 & \delta_{2}
\end{array}\right)\left(\begin{array}{l}
\operatorname{sign}\left(\mathrm{S}_{4}\right) \\
\operatorname{sign}\left(\mathrm{S}_{5}\right)
\end{array}\right)+\left(\begin{array}{cc}
\mathrm{m}_{1} & -\mathrm{m}_{2} \\
\mathrm{~m}_{2} & \mathrm{~m}_{1}
\end{array}\right)\left(\begin{array}{l}
\mathrm{e}_{1} \\
\mathrm{e}_{2}
\end{array}\right)\right] \\
& =\mathrm{S}_{4}\left[\mathrm{~h}_{1}-\delta_{1} \operatorname{sign}\left(\mathrm{S}_{4}\right)\right]+\mathrm{S}_{5}\left[\mathrm{~h}_{2}-\delta_{2} \operatorname{sign}\left(\mathrm{S}_{5}\right]\right.
\end{aligned}
$$

Where,

$$
\left\{\begin{array}{l}
\mathrm{h}_{1}=\mathrm{e}_{3}+\mathrm{m}_{1} \mathrm{e}_{1}-\mathrm{m}_{2} \mathrm{e}_{2} \\
\mathrm{~h}_{2}=\mathrm{e}_{4}+\mathrm{m}_{2} \mathrm{e}_{1}+\mathrm{m}_{1} \mathrm{e}_{2}
\end{array}\right.
$$

To ensure the attractiveness of the surface $S=0$, it is sufficient that the following conditions are satisfied:

$$
\delta_{1} \succ\left|\mathrm{h}_{1}\right|_{\max } \text { And } \delta_{2} \succ\left|\mathrm{h}_{2}\right|_{\max }
$$

\section{B. Dynamics of sliding surface}

The invariance property of $S$ makes it possible to obtain the equivalent vector $\tilde{I}_{s}$. Thus, on the sliding surface, the dynamic (46) becomes:

$$
\left[\begin{array}{l}
0 \\
0
\end{array}\right]=\left[\begin{array}{l}
\mathrm{e}_{3} \\
\mathrm{e}_{4}
\end{array}\right]-\left[\begin{array}{cc}
\delta_{1} & 0 \\
0 & \delta_{2}
\end{array}\right] \mathrm{I}_{\mathrm{s}}
$$

The vector $I_{s} \equiv \tilde{I}_{s}$ is equal to $\tilde{\mathrm{I}}_{\mathrm{s}}=\left[\begin{array}{l}\frac{\mathrm{e}_{3}}{\delta_{1}} \\ \frac{\mathrm{e}_{4}}{\delta_{2}}\end{array}\right]$

With the latter expression, the reduced order system is thus written

$$
\left[\begin{array}{c}
\dot{e_{3}} \\
\cdot \\
\mathrm{e}_{4}
\end{array}\right]=\left[\begin{array}{cc}
-\mathrm{a}_{5}-\frac{\Lambda_{31}}{\delta_{1}} & -\mathrm{x}_{5}-\frac{\Lambda_{32}}{\delta_{2}} \\
\mathrm{x}_{5}-\frac{\Lambda_{41}}{\delta_{1}} & -\mathrm{a}_{5}-\frac{\Lambda_{42}}{\delta_{2}}
\end{array}\right]\left[\begin{array}{l}
\mathrm{e}_{1} \\
\mathrm{e}_{2}
\end{array}\right]
$$

The correction gains $\Lambda_{3}$ and $\Lambda_{4}$ are calculated by identification with an equivalent system with dynamics that ensures the desired behaviour, namely:

$$
\left[\begin{array}{c}
\cdot \\
e_{3} \\
\cdot \\
e_{4}
\end{array}\right]=-\left[\begin{array}{cc}
\mathrm{q}_{1} & 0 \\
0 & \mathrm{q}_{2}
\end{array}\right]\left[\begin{array}{l}
\mathrm{e}_{1} \\
\mathrm{e}_{2}
\end{array}\right] \text { With } \mathrm{q}_{1}, \mathrm{q}_{2} \succ 0
$$


Finally,

$$
\left[\begin{array}{l}
\Lambda_{3} \\
\Lambda_{4}
\end{array}\right]=\left[\begin{array}{ll}
\Lambda_{31} & \Lambda_{32} \\
\Lambda_{41} & \Lambda_{42}
\end{array}\right]=\left[\begin{array}{cc}
\left(\mathrm{q}_{1}-\mathrm{a}_{5}\right) \delta_{1} & -\mathrm{x}_{5} \delta_{2} \\
\mathrm{x}_{5} \delta_{1} & \left(\mathrm{q}_{2}-\mathrm{a}_{5}\right) \delta_{2}
\end{array}\right]
$$

\section{Sliding Mode Based on MRAS rotor speed observer}

The structure of a sliding mode-Based on reference frame mode reference adaptive system (RF-MRAS) for a rotor speed observer is shown in Figure 3.The scheme consists of two models; the first is the reference model, and the second is an adjustable model. The error between the states of the two models is fed to an adaptation mechanism to generate an estimated value of the rotor speed which is used to adjust the adaptation model.

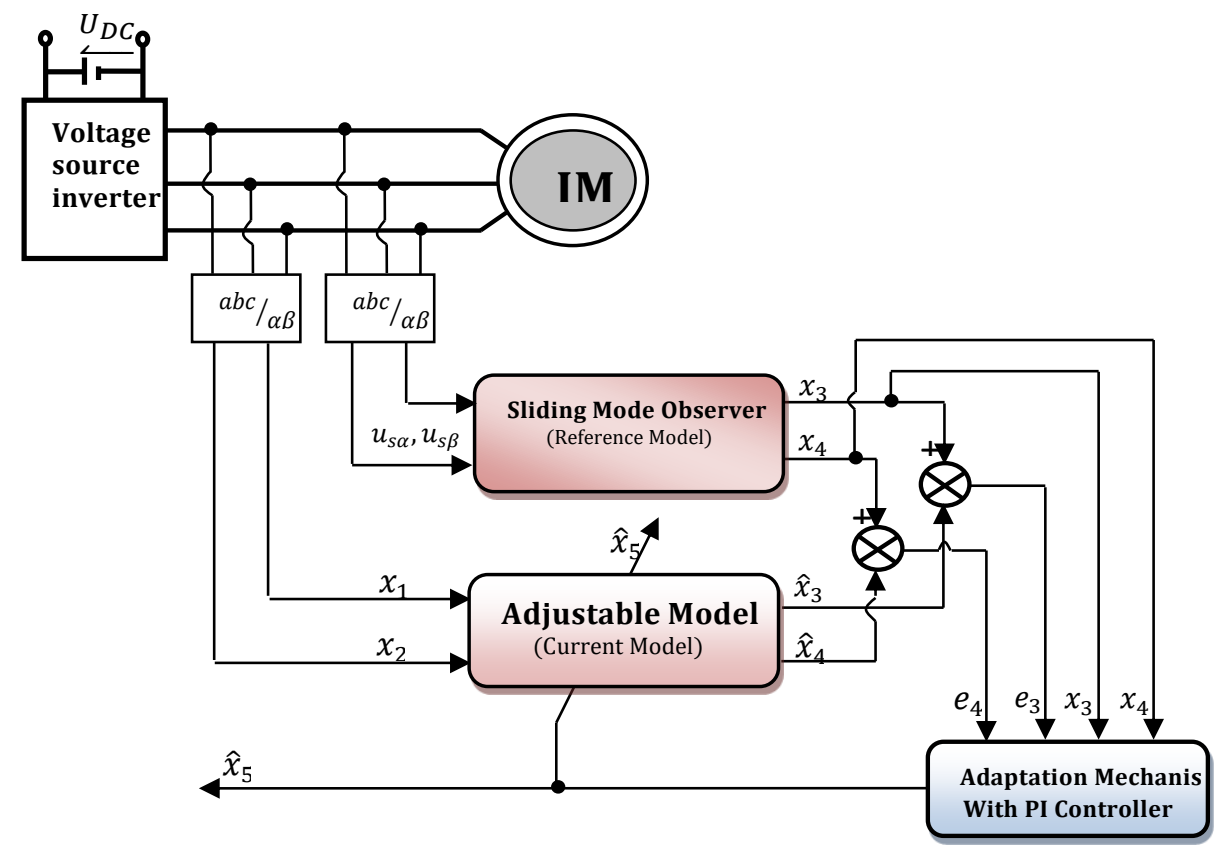

Figure 3. Proposed SMO- Based MRAS for Rotor Speed Estimation Scheme.

\section{A. Reference Model}

The reference model, usually expressed by the voltage model, represents the stator equation. It generates the reference value of the rotor flux components in the stationary reference frame. Since the monitored stator, voltage and current components and these are obtained from the reference model as follows [13-18]:

$$
\left\{\begin{array}{l}
\dot{x}_{3}=\frac{L_{r}}{M}\left(u_{s \alpha}-R_{s} x_{1}-\sigma L_{s} \frac{d x_{1}}{d t}\right) \\
\dot{x}_{4}=\frac{L_{r}}{M}\left(u_{s \beta}-R_{s} x_{2}-\sigma L_{s} \frac{d x_{2}}{d t}\right)
\end{array}\right.
$$

\section{B. Adjustable Model}

The adaptive model, usually represented by the current model, describes the rotor equation and the rotor flux components are expressed in terms of stator current components and the rotor speed. The adaptive model can be expressed in terms of the following equations [13-18]: 


$$
\left\{\begin{array}{l}
\dot{\mathrm{x}}_{3}=\mathrm{a}_{5}\left(M \mathrm{x}_{1}-\hat{\mathrm{x}}_{3}\right)-\hat{\mathrm{x}}_{5} \hat{\mathrm{x}}_{4} \\
\dot{\mathrm{x}}_{4}=\mathrm{a}_{5}\left(M \mathrm{x}_{2}-\hat{\mathrm{x}}_{4}\right)+\hat{\mathrm{x}}_{5} \hat{\mathrm{x}}_{3}
\end{array}\right.
$$

In the new, structure SMO Based-MRAS. The sliding observer of the rotor flux is used as a reference model due to the good performances, especially in terms of robustness and the current model and to recalibrate with respect to this model for the estimation of the speed $\hat{x}_{5}$.

For simplicity, we define the following estimation errors, respectively, of speed and rotor flux:

$$
\left\{\begin{array}{l}
\mathrm{e}_{3}=\mathrm{x}_{3}-\hat{\mathrm{x}}_{3} \\
\mathrm{e}_{4}=\mathrm{x}_{4}-\hat{\mathrm{x}}_{4} \\
\mathrm{e}_{5}=\mathrm{x}_{5}-\hat{\mathrm{x}}_{5}
\end{array}\right.
$$

Then, the derivative of the rotor flux error can be represented as:

$$
\left\{\begin{array}{l}
\mathrm{e}_{3}=-\mathrm{a}_{5} \mathrm{e}_{3}-\mathrm{x}_{5} \mathrm{x}_{4}+\hat{\mathrm{x}}_{5} \hat{\mathrm{x}}_{4} \\
\dot{\mathrm{e}_{4}}=-\mathrm{a}_{5} \mathrm{e}_{4}+\mathrm{x}_{5} \mathrm{x}_{3}-\hat{\mathrm{x}}_{5} \hat{\mathrm{x}}_{3}
\end{array}\right.
$$

By considering the relation (58), we can rewrite (59) as follows:

$$
\left\{\begin{array}{l}
\dot{e_{3}}=-a_{5} e_{3}-e_{5} x_{4}-\hat{x}_{5} \hat{x}_{4} \\
e_{4}=-a_{5} e_{4}+e_{5} x_{3}+\hat{x}_{5} \hat{x}_{3}
\end{array}\right.
$$

In order to study the stability condition of the observer's, and then determine the adaptation mechanism that gives us the speed estimation, we can chose the Lyapunov function as follows [8]:

$$
\mathrm{V}_{4}=\frac{1}{2} \mathrm{e}_{3}^{2}+\frac{1}{2} \mathrm{e}_{4}^{2}+\frac{\mathrm{e}_{5}^{2}}{2 \mu}
$$

Where $\mu$ is a positive constant.

The Lyapunov function derivative is as below:

$$
\dot{\mathrm{V}}_{4}=\mathrm{e}_{3} \mathrm{e}_{3}+\mathrm{e}_{4} \dot{\mathrm{e}}_{4}+\frac{\mathrm{e}_{5} \dot{\mathrm{e}}_{5}}{\mu}=-\mathrm{a}_{5}\left(\mathrm{e}_{3}^{2}+\mathrm{e}_{4}^{2}\right)+\mathrm{e}_{5}\left(\frac{\dot{\mathrm{e}_{5}}}{\mu}+\mathrm{e}_{4} \mathrm{x}_{3}-\mathrm{e}_{3} \mathrm{x}_{4}\right)
$$

In order to guarantee $\dot{V}<0$ (negative definite), we can for example force the second term to be null. We obtain:

$$
\frac{\mathrm{e}_{5}}{\mu}+\mathrm{e}_{4} \mathrm{x}_{3}-\mathrm{e}_{3} \mathrm{x}_{4}=0 \Rightarrow \dot{\mathrm{V}}=-\mathrm{a}_{5}\left(\mathrm{e}_{3}^{2}+\mathrm{e}_{4}^{2}\right) \prec 0
$$

We have:

$$
\dot{\mathrm{e}}_{5}=-\dot{\hat{x}}_{5} \Rightarrow \frac{\dot{\hat{x}}}{\mu}=e_{4} x_{3}-e_{3} x_{4}
$$

However, this adaptive law of the speed

$$
\hat{\mathrm{x}}_{5}=\mu \int\left(\mathrm{e}_{4} \mathrm{x}_{3}-\mathrm{e}_{3} \mathrm{x}_{4}\right) \mathrm{dt}
$$

For augmented the dynamic of this observer during the transitory phase of rotor speed, we estimate the speed by large PI regulators. Then

$$
\hat{\mathrm{x}}_{5}=\mathrm{K}_{\mathrm{p}}\left(\mathrm{e}_{4} \mathrm{x}_{3}-\mathrm{e}_{3} \mathrm{x}_{4}\right)+\mathrm{K}_{\mathrm{i}} \int\left(\mathrm{e}_{4} \mathrm{x}_{3}-\mathrm{e}_{3} \mathrm{x}_{4}\right) \mathrm{dt}
$$

Where $K_{P}$ and $K_{i}$ are adaptive gains for speed estimator. 


\section{Simulation Results}

In order to test the static and dynamic performance of the sliding mode direct torque control strategy SM-DTC without a speed sensor provided by a SMO sliding-mode observer based on the MRAS estimation technique we use for the induction motor, simulation tests using Matlab / Simulink software have been realized and discussed in this section. The parameters of the 15 KW induction motor used in the simulation are given in Table 1 . The rotor flux reference has been fixed to $0.8 \mathrm{~Wb}$.

The parameters of the $15 \mathrm{Kw}$ induction motor used in the simulation are shown in Table 01 . The reference of the rotor flux has been set at $0.8 \mathrm{~Wb}$.

Table 1. Induction Motors Parameters

\begin{tabular}{|l|c|c|c|}
\hline \multicolumn{1}{|c|}{ Name } & Parameters & Unit & Value \\
\hline Rotor Inductance & $\mathrm{L}_{\mathrm{r}}$ & $\mathrm{H}$ & 0.000991 \\
\hline Stator Inductance & $\mathrm{L}_{\mathrm{s}}$ & $\mathrm{H}$ & 0.000991 \\
\hline Mutual Inductance & $\mathrm{M}$ & $\mathrm{H}$ & 0.06419 \\
\hline Stator Resistance & $\mathrm{R}_{\mathrm{s}}$ & Ohm & 0.2147 \\
\hline Rotor Resistance & $\mathrm{R}_{\mathrm{r}}$ & Ohm & 0.2205 \\
\hline Number of poles & $\mathrm{p}$ & $/$ & 2 \\
\hline Motor - Load inertia & $\mathrm{J}$ & $\mathrm{Kg} . \mathrm{m}^{2}$ & 0.102 \\
\hline Rated Power & $\mathrm{P}_{\mathrm{n}}$ & $\mathrm{KW}$ & 15 \\
\hline Viscous Friction coefficient & $\mathrm{f}_{\mathrm{c}}$ & N.m.s & 0.009541 \\
\hline
\end{tabular}

Table 2. SMDTC and SMO-Based MRAS parameters

\begin{tabular}{|c|c|}
\hline SM-DTC Parameters & SMO Parameters \\
\hline$\mu_{1}=20$ & $\mathrm{~K}_{\mathrm{P}}=10^{5}$ \\
\hline$\mu_{2}=20$ & $\mathrm{~K}_{\mathrm{i}}=2.10^{5}$ \\
\hline$\varepsilon_{1}=800$ & $\mathrm{q}_{1}=2.10^{4}$ \\
\hline$\varepsilon_{2}=800$ & $\mathrm{q}_{2}=2,5.10^{4}$ \\
\hline $\mathrm{C}_{1}=0.1$ & $\delta_{1}=10^{-5}$ \\
\hline $\mathrm{C}_{2}=100$ & $\delta_{2}=10^{-5}$ \\
\hline$\lambda=-12$ & $\mu=2.10^{6}$ \\
\hline \multicolumn{2}{|c|}{$\mathrm{B}=0.5$} \\
\hline
\end{tabular}

We will give in Table 02, the values of the gains that we chose during the simulation of the SMDTC equipped with a speed control loop by a sliding mode controller SMC, and associated with a SMO based on the MRAS estimation technique proposed for the estimated speed of rotor for the induction motor. Initially, the reference speed $\left(x_{5}^{r e f}\right)$ was set at $100 \mathrm{rad} / \mathrm{s}$ between the time interval $t=0 \mathrm{~s}$ and $\mathrm{t}=3 \mathrm{~s}$, under the application of a load torque $\mathrm{T}_{\mathrm{L}}$ equal to $27 \mathrm{Nm}$ between instants $t=1 \mathrm{~s}$ and $\mathrm{t}=2.5 \mathrm{~s}$, then the speed reference then imposes a reversal of direction of rotation to $-100 \mathrm{rad} / \mathrm{s}$. Followed between $\mathrm{t}=3 \mathrm{~s}$ and $\mathrm{t}=4 \mathrm{~s}$ of a constant speed regime. A second inversion is imposed from $\mathrm{t}=4 \mathrm{~s}$, to reach a reference speed $x_{5}^{r e f}=10 \mathrm{rad} / \mathrm{s}$, where the speed is very low. This phase will aim to test the behavior of the control strategy proposed at low speed in conditions close to the critical operating zone (no-observability of the machine). A third inversion to reach again the reference speed $x_{5}^{r e f}=100 \mathrm{rad} / \mathrm{s}$ at time $\mathrm{t}=5.5 \mathrm{~s}$ (see Figure 4 (a)).

Figures 4(a) and (b) show the evolution of the actual speed $\left(x_{5}\right)$ and the estimated speed $\left(\hat{x}_{5}\right)$, and the estimation error. When the motor starts empty between instants of time $t=0$ s and $\mathrm{t}=1 \mathrm{~s}$, it is found that, the real and estimated speed join its reference $\left(x_{5}^{\mathrm{ref}}=100 \mathrm{rad} / \mathrm{s}\right)$ with a very fast response time (from the order of $0.28 \mathrm{~s}$ ) without overshot, and the estimated speed $\left(\hat{x}_{5}\right)$ by the SMO approach based on the MRAS estimator perfectly follows the actual speed 
with an estimate error of almost zero (equal to $0.01 \mathrm{rad} / \mathrm{s}$ at maximum see Figure 4 (b)) and has small oscillations. When we increase the load torque from 0 N.m. to $27 \mathrm{Nm}$ between time intervals $\mathrm{t}=1 \mathrm{~s}$ and $\mathrm{t}=2.5 \mathrm{~s}$, the estimated and actual motor speed decreases by about $0.18 \mathrm{rad} / \mathrm{s}$ of its reference value. Then stabilizes at $100 \mathrm{rad} / \mathrm{s}$. it is also clear that the SM-DTC control strategy associated with an MRAS-based SMO is robust with respect to the variation of the reference speed, since the estimated and actual speed rate tracks the reference speed at start up as at the reversal of direction of rotation, in a very satisfactory way with minor deviations during changes of speed (Figure 4 (b)). We can clearly see the dynamic insensitivity of the proposed strategy for the low speed induction motor.

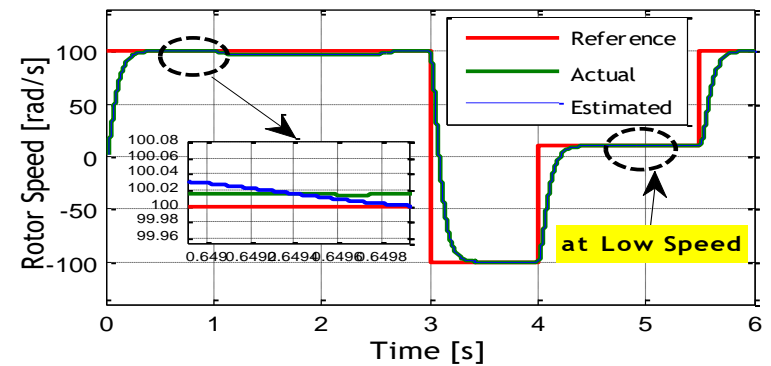

(a)

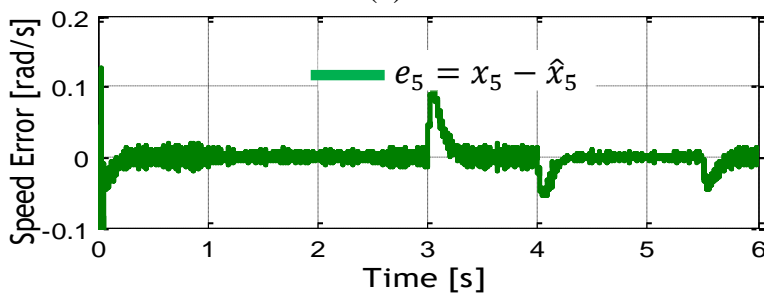

(b)

Figure 4. Simulation results: (a) rotor speed, (b) Error between estimated and actual rotor speeds

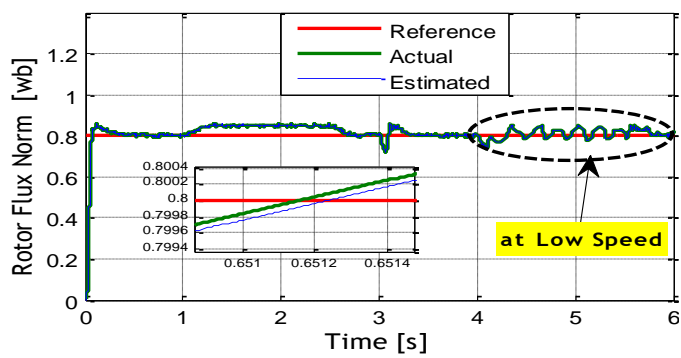

(a)

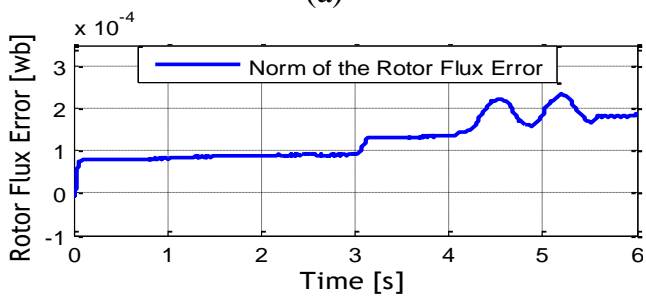

(b)

Figure 5. Simulation results: (a) rotor flux norm, (b) Error between estimated and actual rotor flux norm 
Figures 5 (a) and (b) showing the actual and estimated rotor flux modulus evolution and the estimation error. These responses show a good estimate of actual and estimated flux module tracking to the desired value, with a low flux ripple of around $2.2 \%$ and an estimate error (Figure 5 (b)) of almost zero (of the order of $2 \times 10^{-4} \mathrm{~Wb}$ ). Figure 5 (a) shows a slight oscillation on the flux response when a low speed is applied.

Figure 6 shows the evolution of electromagnetic torque estimated. A good convergence of estimated torque is observed towards the imposed load torque value. We can also see the appearance of the peaks on the estimated torque response (equal to $-74 \mathrm{Nm}, 45 \mathrm{Nm}$ and $40 \mathrm{Nm}$ respectively) during the inversion of the speed which is stabilized by the following. Moreover, the application of the SM-DTC strategy based on the SVM technique proves its efficiency by allowing the reduction of the torque ripples (the torque ripple is of the order of $3 \%$ ).

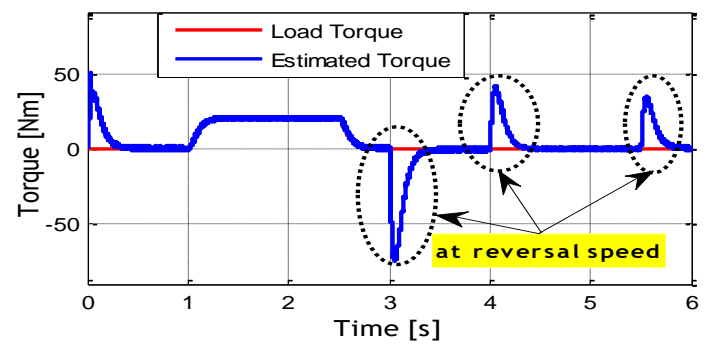

Figure 6. Electromagnetic torque

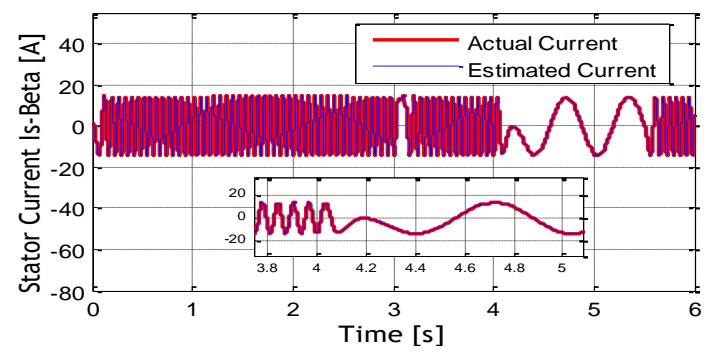

(a)

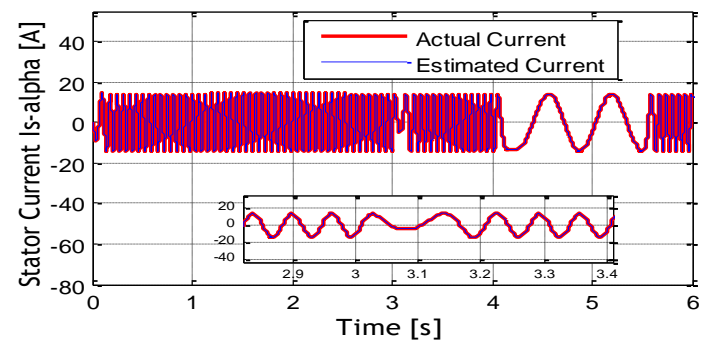

(b)

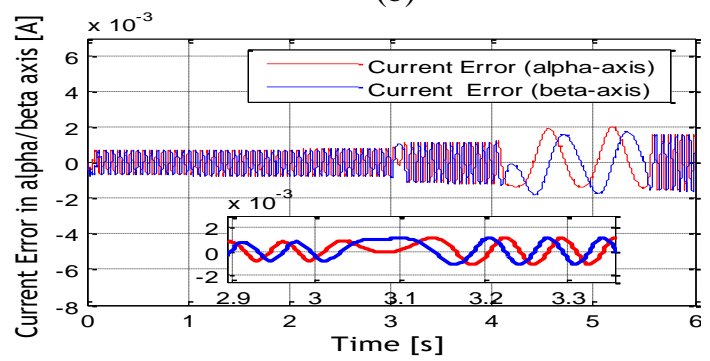

(c)

Figure 7. Simulations results: (a) and (b) Estimated and actual Stator currents in $(\alpha-\beta)$ axis, (c) Error between estimated and actual stator currents in $(\alpha-\beta)$ axis. 
Figures 7(a), (b) and (c) respectively show the evolution of the components along the axes $(\alpha$ - $\beta$ ) of the actual and estimated stator currents and the estimation error. Note that the stator current components estimated $\left(\hat{x}_{1}, \hat{x}_{2}\right)$ are merged with the real components $\left(x_{1}, x_{2}\right)$, have almost a sinusoidal shape without distortion. The estimation error (Figure 7 (b)) is practically zero (of the order $2 \times 10^{-4} A$ maximum). The paces obtained show the effectiveness of the MRAS-based SMO observer proposed in this study.

Figures 8 (a), (b) and (c) show the evolution of the components along the axes $(\alpha-\beta)$ of the actual and estimated rotor flows and the estimation error. From these responses we can see that the estimated values of the rotor flux $\left(\hat{x}_{3}, \hat{x}_{4}\right)$ coincide perfectly with those of the real quantities. The estimation error is very small (about $1,2 \times 10^{-4} \mathrm{~A}$ maximum).

In addition, Figure 9 shows the evolution of the estimated rotor flux path, we can notice that they follow perfectly their circular trajectories in a thick month band.

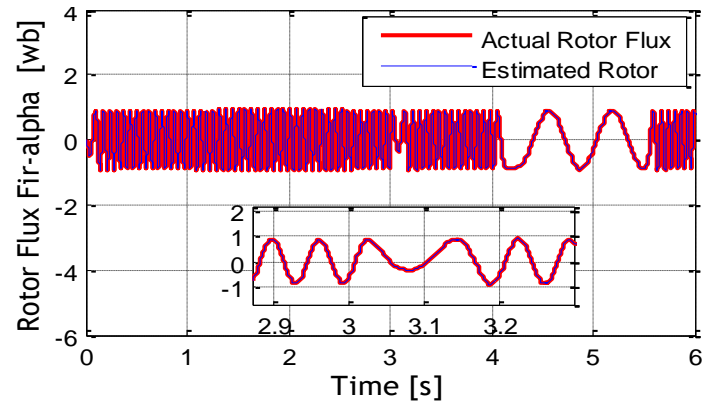

(a)

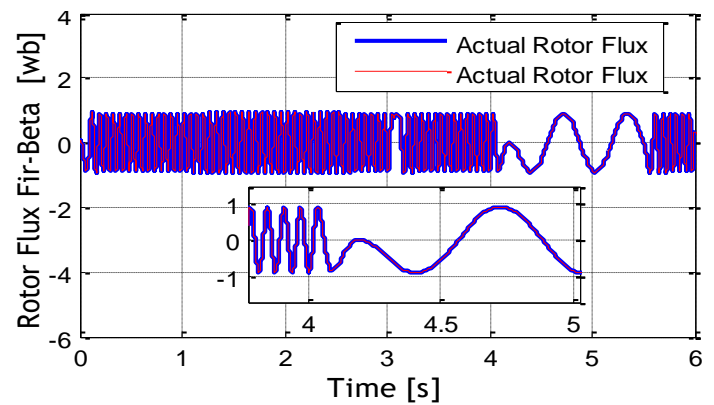

(b)

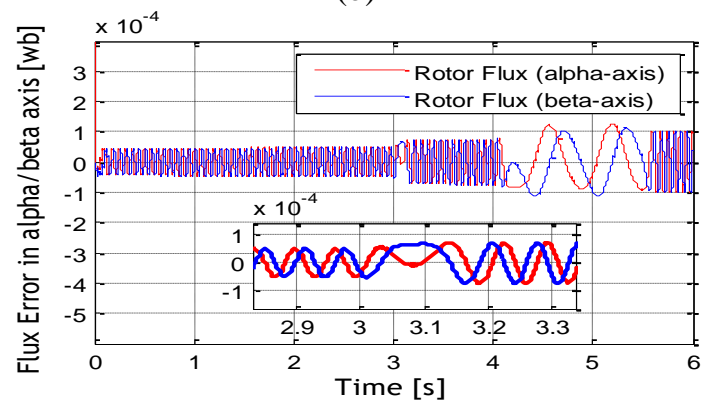

(c)

Figure 8. Simulations results: (a) and (b) Estimated and actual rotor flux in $(\alpha-\beta)$ axis, (c) Error between estimated and actual rotor flux in $(\alpha-\beta)$ axis. 


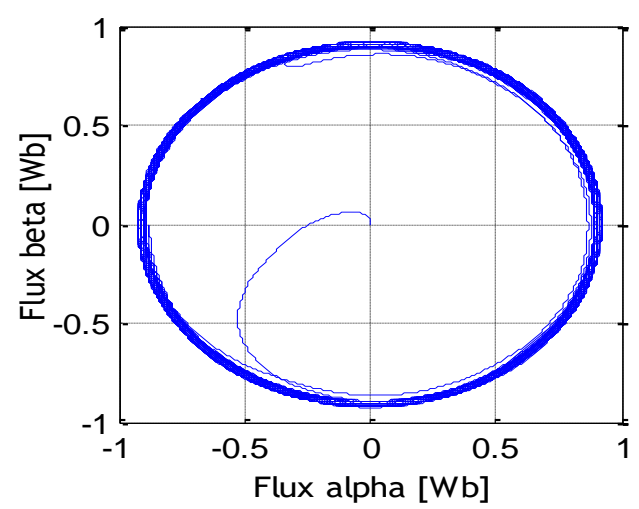

Figure 9. Rotor flux trajectories

\section{Conclusions}

This paper presents the application of sliding mode technique for Sensorless direct torque control (DTC) combined with space vector modulation (SVM), associated to the sliding mode observer-based MRAS technique for estimation of rotor speed of an induction motor. From the simulation results we can observe the performance of the proposed SM-DTC controller was found superior in different operating condition; such as, a step change in command speed and external load disturbances. Furthermore, the SM-DTC reduced the Rotor flux and torque ripples. Acknowledgements

This work was supported by the Laboratory of Smart Grids and Renewable Energies (S.G.R.E). Faculty of Technology, Department of Electrical Engineering, Bechar University, Algeria.

\section{References}

[1] C. Chan, "The state of the art of electric and hybrid vehicles", in Proceedings of the IEEE, 2002, Vol. 90(2), pp. 247-275.

[2] C.Martins and A. S., "Technological trends in induction motor electrical drives", in IEEE Power Tech, 2001.

[3] R. S. Tripathi Anbarasu and R.Somakumar, "Control of AC motor drives: performance evaluation of industrial state of art and new technique", in IEEE Int. Conf. Industrial Tech. (ICIT) , 2006, pp. 3049 -3054.

[4] L.Baghli, "Contribution à la commande de la machine asynchrone: Utilisation de la logique floue, des réseaux de neurones et des algorithmes génétiques", Thèse doctorat, Université Henri Poincaré, Nancy-I, 1999.

[5] P. Pohjalainen, P.Tiitinen, and J. Lalu, "The next-generation motor control method-direct torque control, DTC”, In Conf. Rec., 1994, EPE'94, pp. 115-120.

[6] D.Casadei, G. Serra, and A.Tani, "Implementation of a direct torque control algorithm for induction motors based on discrete space vector modulation", in IEEE Trans Power Electron., July 2000, Vol. 15, pp. 769-777.

[7] G. Habetler T, F.Profumo, M.Pastorelli, and L. M.Tolbert, "Direct torque control of induction machines using space vector modulation", in IEEE Trans. Ind. Applicat., Sept. /Oct. 1992 vol. 28, pp. 1045-1053.

[8] C.Lascu, I. Boldea, and F. Blaabjerg, "A modified direct torque control for induction motor Sensorless drive”, in IEEE Trans. Ind. Applicat., Jan. /Feb. 2000, Vol.36, pp. 122-130.

[9] V.Utkin, J.Guldner, and J.Shi, "Sliding Mode Control in Electromechanical Systems", New York: Taylor \& Francis, 1999.

[10] A.Benchaib, A.Rachid, E.Audrezet, and M.Tadjine, "Real-time Sliding-mode observer and control of an induction motor", in IEEE Trans. Ind. Electron.,Feb. 1999, vol. 46, pp. 128137. 
[11] H.Rasmussen, P.Vadstrup, H.Borsting, "Nonlinear field oriented control of induction motors using the Backstepping design".

[12] S K.Lin, C H.Fang, "Sliding-mode direct torque control of an induction motor", in IEEE Ind. Electr. Conf. 2001(IECON'01), pp.2171-7.

[13] R.Beguenane, H. Benbouzid M, M.Tadjine and A.Tayebi, "Speed and rotor time constantestimation via MRAS strategy for induction motor drives", in Electricmachines anddrives conference record IEEE international. pp. 18-21, May 1997.

[14] M.Djemai, J.Hernandez, J.P Barbot: "Nonlinear Control with Flux Observer for Singularly Perturbed Induction Motor", in IEEE Conference on Decision and Control, Dec. 1993 Vol. 4, San Antonio,TX, USA, pp. 3391 - 3396.

[15] G C.Verghese, "Observers for Flux estimation in Induction Machines", in IEEE Trans. on Ind. Elec., February 1988 Vol. 35 (1), pp. 85-94.

[16] V.I. Utkin, "Sliding mode control design principals and applications to electric drives", in IEEE Trans. Ind. Electron, 1993, 40, pp.26-36.

[17] S.Drakunov, S.Utlun: "Sliding Mode Observers", in 34th IEEE CDC, New Orleans, LA, USA, 1995 , pp. $3376-3378$.

[18] H. Tajimaand, Y. Hori: "Speed senseless field orientation control of the induction machine". in IEEE Trans. Indus. Applic. , Jan/Feb 1993, Vol. 29 (1), pp. 175-180.

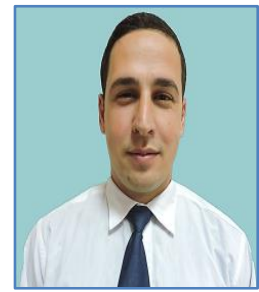

Abdelkader GHEZOUANI was born in Tlemcen, Algeria, in 1989. He graduated from the University of Tlemcen, having received L.Sc. and M.Sc. degrees in Electrical Engineering in 2009 and 2011 respectively. Since 2015, he has been a Ph.D. Candidate in the Department of Electrical Engineering at the University of Bechar, Algeria. His research interests include sliding mode control, Non-Linear Control, especially the control of electrical machines with applications to Electrical Vehicle Drive.

E-mail address: gheabd@ymail.com.

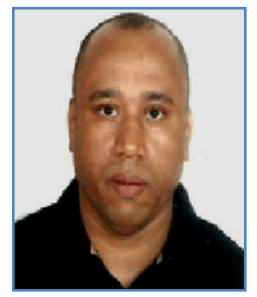

Brahim GASBAOUI received his electrical engineering diploma from the University Ibn-Khaldun of Tiaret in 1993, and an MS degree in 2008 from Bechar University, Algeria. Also, he got his Ph.D. degree from the Faculty of Sciences and Technology of Bechar University. He is currently a teacher of electrical engineering at Bechar University. His research interests include power electronics robust control for electric vehicle and propulsion system, power electronics, antilock brake systems, anti-skid control for electric vehicles drive.

E-mail address: gasbaoui_2009@yahoo.fr.

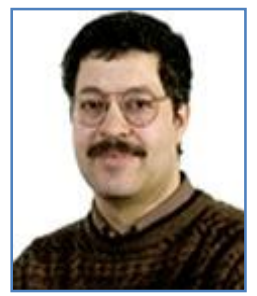

Jamel GHOUILI was born in Ghardimaou, Tunisia, in 1962. He is currently Professor at the University of Moncton, Canada. He is responsible of the power electronics and drives Teaching and Research program since 2000. He received his B.Sc., M.Sc. and Ph.D. degrees from the University of Québec at Trois Rivières, Canada, in 1986, 1998, and 2004 respectively. Early in his career, he served as Professor at Ecole Polytechnique de Masuku, Gabon. His main research interests include power converters, AC drives, DSP and FPGA control, sensorless control, EV/HEV drives, fuzzy logic and neural network applications in power electronics and drives. 